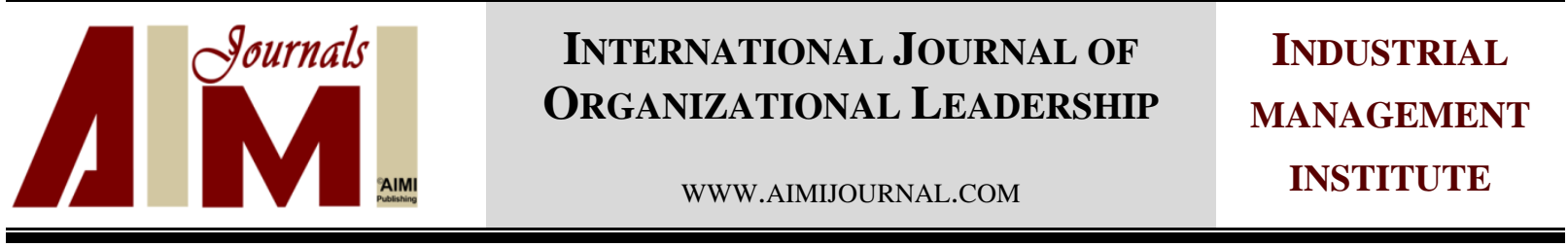

\title{
Strategic entrepreneurship and dynamic flexibility: Towards an integrative framework
}

\author{
Pereira Renato ${ }^{1, *}$, Omar M. Naguib ${ }^{2}$ \\ ${ }^{1}$ OBSERVARE/UAL, Lisbon, Portugal; ISCTE-IUL, Lisbon, Portugal; ISCTEM, Maputo, Mozambique \\ ${ }^{2}$ ISCTEM, Maputo, Mozambique; OBSERVARE/UAL, Lisbon, Portugal
}

\begin{abstract}
Keywords:

Strategic Entrepreneurship,

Dynamic Flexibility,

Change

Strategic entrepreneurship is a growing field within both Entrepreneurship and Management Science. Dynamic flexibility is a concept originally developed to resolve general business issues (Apter, 1985) and later enhanced to address specific strategic management challenges. Strategic Entrepreneurship deals with a singular strategic

Received

06 November 2015 management response which is to achieve superior performance via simultaneous opportunity-seeking and advantage-seeking activities (Ireland, Hitt, \& Simon, 2003). The process of maintaining superior performance is certainly a longitudinal one and requires capabilities on both those dimensions (Ireland \& Webb, 2007). In this paper, we propose

Received in revised form 11 July 2016

Accepted

01August 2016 the use of dynamic flexibility as a useful capability to address strategic entrepreneurship longitudinal issue. By exploring the modulation time response model and different other references from both strategic management and strategic entrepreneurship literature, we

Correspondence:

pereiren@hotmail.com aim to establish an integrative framework for dynamic strategic entrepreneurship.
\end{abstract}

(C)AIMI Journals

Strategic entrepreneurship is a growing field within both entrepreneurship and management Science. Seminal work from Burgelman (1983) established the link between (corporate) entrepreneurship and strategic management and ever since this research stream is increasing in scholar production. In 2007, the most prestigious society for the study of strategic management - the strategic management society - has created a periodic fully devoted to strategic entrepreneurship issues and challenges - the Strategic Management Journal. On the other hand, the acknowledgement of the so called longitudinal issue of strategic management was formalized some 25 years ago (Porter, 1991) and initiated a solid tradition of research on the 
dynamic variables of strategic management. The novelty about strategic entrepreneurship is that it enlarged Porter's view of strategic management as a process of achieving superior performance through the creation and maintenance of a competitive advantage (Porter, 1980, 1985) by adding up the contribution of opportunity-seeking activities (Ireland et al., 2003). Nevertheless, studying strategic management/strategic entrepreneurship processes in a longitudinal perspective is not quite the same thing as studying the dynamic capabilities underlying a dynamic strategic response responsible for long-term strategic adjustment to market conditions, regardless of the need for a clear and identified competitive advantage. At the same time, inflexible strategic positioning somehow defended as the only true strategy (Porter, 1996), was increasingly challenged in both theoretical and empirical arenas raising the importance of flexibility and adaptive strategic behavior for a huge number of firms, especially small and medium size companies and about $90 \%$ of all corporations in the world. Finally, the so called dynamic capabilities of the firm, broadly defined as the specific routines required to address high speed environments (Eisenhardt \& Martin, 2000; Teece, Pisano, \& Shuen, 1997) again are not themselves dynamic in the temporal sense of the concept but rather strategic actions designed to cope with the challenges of a constantly changing environment, once called 'turbulent' (Ansoff, 1984).

\section{Strategic Entrepreneurship \\ Choice}

As like the other disciplines within management science, corporate entrepreneurship has been concerned with the process of wealth creation; but unlike others, entrepreneurship focused primarily in the early stages of a new business venture, their antecedents and consequences, having new and emerging opportunity identification as its central basis for success (Shane and Venkataraman, 2000). Recent research, however, highlighted that not only entrepreneurial approach overcomes the early stages of a business but also that wealth creation both relates to marketplace opportunity recognition and to converting opportunities into competitive advantages (Ketchen, Ireland, \& snow, 2007) and maintaining those dynamically, i.e., throughout time. This process of maintaining superior performance in the long term has long been a critical challenge to industrial organization scholars. In his powerful and eloquent work, Porter (1991) assessed the progress of strategic management towards establishing a complete dynamic theory. The longitudinal problem in opposition to the cross-sectional problem was defined as the understanding of a firm's process by which its goals are achieved as time evolves. Simplistically, strategy appeared to be a path-dependency algorithm linked to initial (entrepreneurial) choices such as business economic activity choosing.

\section{Strategic Flexibility}

As early as 1980, strategic flexibility was described as the possibility of voluntarily introducing strategic change to alter firm performance (Nadkarni \& Narayanan, 2007). One of the earliest works where strategic flexibility was conceptualized studied the connection between exit barriers and rigid firm behavior (Harrigan, 1980). Throughout time, this concept was somehow restricted and quoted mainly in the context of product development (Sanchez, 1995). Worren, Moore, and Cardona (2002) has the same approach. Unsurprisingly, most valuation discussions conducted by venture capital investors focus precisely on company versus product when 
assessing venture's strategic extension. For strategic entrepreneurship purposes, strategic flexibility seemed to be an interesting concept because it presented a new perspective to entrepreneurs better take advantage of opportunities deriving from gaps in the marketplace, while pursuing a competitive advantage. The unresolved problem by strategic flexibility was the apparent paradox that it generated: How good can my strategy be if I keep on changing it all the time? In other words, being flexible is about changing everything all the time or just a few things in specific moments. In addition, what kind of things should be changed to actually produce an enduring competitive effect?

\section{Strategic Adaptation}

Naturally, the expected outcome of strategic flexibility is strategic adaptation or, as was put by many, strategic fit. Zajac, Kraatz, and Bresser (2000) showed evidence of the possibility of a normative approach to strategic change. After 1990s, prolix research results sustaining industrial organizational hypotheses of industry influence over company performance, strategic management appears now to be a process completely guided by environmental stimuli with fully predictable outcome. Furthermore, the timing, direction, and magnitude of strategic changes can be logically predicted based on differences in specific environmental forces and organizational resources. Assuming this perspective correct and both theoretically and empirically supported, what is the room for strategic choice, for strategic surprise, and even for ploy, once basic attributes of a strategic management tool set?

\section{Dynamic Flexibility}

As seen earlier in this work, strategic entrepreneurship is about combining strategic management with corporate entrepreneurship to resolve a firm's wealth creation problem. Taking effective advantage of marketplace opportunities require companies to come up with the right solution at the right time, i.e., within a certain window of opportunity (Abell, 1978). In other words, entrepreneurs face two different yet simultaneous types of problems including the complexity-variety problem and the time-resource problem.

\section{The Complexity-Variety Problem}

The complexity-variety problem also known in the literature as the 'Ashby Law' (Ashby, 1956), is the issue of overcoming market gaps from the offer side of the marketplace by delivering the right product to consumers. The 'right product' is the one that customers actually pay for because it has a clear positive impact in their value chain, utility function, and satisfaction needs. In this sense, the complexity-variety problem is a very simple game; either the entrepreneur is able to generate the right offer to the market and wins the game or he/she is unable to deliver the right response to the market and looses the game. Because product development and innovation management in general require long term cycles, before a sustainable flow of new stuff could be pumped in to the market by an entrepreneurial venture and because institutional investors require heavy control systems in place to fund a new company, most entrepreneurs are obliged to prepare everything in advance adopting product roadmap processes and procedures. This has a very important consequence, which indicates that entrepreneurs must resolve the complexity-variety problem ahead of time by producing 
inventory of their solutions, thus generating static flexibility for the scenario foreseen by the company.

\section{The Time-Resource Problem}

Approaching marketplace gap resolution, meaning market opportunity-seeking, by preparing complexity-variety solutions based on scenario analysis could be something quite acceptable when entrepreneurs are highly innovative, when they dispose of a clear technological advantage, and when they are strongly competent in anticipating market trends. Such combination of resources and capabilities is, however, very rare among entrepreneurial community. Because most entrepreneurial ventures do not reach critical mass requirements to determine market evolution and also because most markets are too dynamic to allow for long run perspective, entrepreneurs must have the ability to react fast each time the structural landscape changes (Doz \& Kosonen, 2007). Hence, entrepreneurs must consider developing dynamic flexibility capabilities to meet a time-to-market compatible with their markets' windows of opportunity by using non pre-released solutions.

Dynamic flexibility, the ability of reacting to market variations within the window of opportunity by accelerating organizational pace using time-resource reserves is a type of capacity that could be approached within the dynamic capabilities of the firm (Eisenhardt \& Martin, 2000; Teece et al., 1997). Designed to address high speed markets, this framework is particularly useful to support strategic entrepreneurship facing the type of uncertainty outlined earlier in this work.

\section{Towards an Integrative Framework}

\section{Starting Point}

According to classic corporate finance theory (Brealey, Meyers, \& Allen, 2013), time is seen as a fixed constraint, usually defined according to financial reporting requirements in a yearly basis. The income reached by an entrepreneurial venture during a financial reporting period (volume) would be $\Delta G=P \times T, T>0$, whereby:

$\Delta G-$ Goal variation, in terms of income level achieved, between the beginning and the end of a given time period (usually, one fiscal year)

$P$ - Profit resulting from the difference between economic inflows and economic outflows (revenues and expenses) during a given time period (usually one fiscal year)

$T$ - Reference time (frame), usually one fiscal year, during which revenue and expenses allow for the delivery of a certain goal (measured by a certain profit level)

\section{Dynamic Time}

Abbel (1978) defined 'window of opportunity' as the available time frame for any given product offered by any given company to achieve optimal time adjustment to (potential) customers demand. This means that 'time' should not be considered in a fixed time-frame basis for dynamic management purposes. This goal can be reached, independently of window of opportunity evolution, by considering that the required complexity-variety will not change ( $\Delta G$ $=$ constant) and is adequate to marketplace requirements. 
With this new perspective, 'time' becomes 'response time', better said, 'time-to-market', a critical variable for strategic entrepreneurship and marketing purposes:

$$
T=\frac{\Delta G}{P}, T>0
$$

whereby:

$\Delta G$ - Fixed Goal, measured by a certain expected income level to be reached, generated by the delivery of a given complexity-variety deemed adequate to demand expectations and needs

$P$ - Entrepreneurial pace, variable, congruent with time-to-market target and related profit evolution

$T$ - Time-to-market, variable, depending on pace changes

With this 'new' time, variable, 'dynamic', the causal connection between the other two parameters become reverse and the performance of the entrepreneurial venture thus managed is no longer a linear one, but a hyperbolic one. Consequently, the time-to-market $(T)$ of a given product generated dynamically as a response to some market change, measured by the correspondent profit target $(G)$ will decrease in the reverse proportion of the venture's pace $(P)$ which must be in line with the relevant window of opportunity and complexity-variety required. Dynamic Flexibility then equals the pace acceleration allowed by the relevant hyperbolic function, correspondent to the difference between the entrepreneurial venture current point and the point corresponding to the expected situation, variable, according to market stimuli and firm's capabilities.

\section{Discussion and Conclusion}

This paper aimed at developing an integrative framework of strategic entrepreneurship and dynamic flexibility. Reviewing key concepts from both strategic management and strategic entrepreneurship literature, we have constructed the entrepreneurial challenge as an adaptive one, requiring entrepreneurial ventures to respond to market opportunities not only in terms of variety-complexity but also within the window of opportunity. Consequently, entrepreneurial ventures are pushed to develop strategic flexibility using capabilities of dynamic adaptation to avoid the risks of relying mainly on static flexibility or inventory. The logical corollary of this work is that dynamic flexibility is a key feature to strategic entrepreneurship. Furthermore, dynamic flexibility can be used and managed by entrepreneurs throughout an integrative framework with powerful modeling tools that was briefly outlined in this research.

\section{References}

Abell, D. F. (1978). Strategic windows. Journal of Marketing, 7, 21-26.

Ansoff, H. I. (1984). Implanting strategic management. Englewood Cliffs, NJ: Prentice Hall.

Apter, J. (1985). Maîtriser la flexibilité de l'entreprise: Une méthode de gestion et ses applications. Paris: Masson.

Ashby, W. R. (1956). An introduction to cybernetics. London: Chapman \& Hall. 
Burgelman, R. A. (1983). Corporate entrepreneurship and strategic management: Insights from a process study. Management Science, 29(12), 1349-1364.

Brealey, R., Meyers, S., \& Allen, F. (2013). Principles of corporate finance (11 ${ }^{\text {th }}$ ed.). New York, NY: McGraw-Hill.

Doz, Y., \& Kosonen, M. (2007). Fast strategy: How strategic agility will help you stay ahead of the game. USA: Wharton School Publishing.

Eisenhardt, K. M., \& Martin, J. A. (2000). Dynamic capabilities: What are they? Strategic Management Journal, 21(10/11), 1105-1121.

Goodstein, J., Boeker, W., \& Stephan, J. (1996). Professional interests and strategic flexibility: A political perspective on organizational contracting. Strategic Management Journal, 17(7), 577-586.

Harrigan, K. R. (1980). The effect of exit barriers upon strategic flexibility. Strategic Management Journal, 1(1), 165-176.

Ireland, R. D., Hitt, M. A., Simon, D. G. (2003). A model of strategic entrepreneurship: The construct and its dimensions. Journal of Management, 29(4), 963-989.

Ireland, R. D., \& Webb, J. W. (2007). Strategic entrepreneurship: Creating competitive advantage through streams of innovation. Business Horizons, 50, 49-59.

Ketchen, D. J., Ireland, R. D., \& Snow, C. S. (2007). Strategic entrepreneurship, collaborative innovation, and wealth creation. Strategic Entrepreneurship Journal, 1(3/4), 371-385.

Nadkarni, S., \& Narayanan, V. K. (2007). Strategic schemas, strategic flexibility and firm performance: The moderating role of industry clockspeed. Strategic Management Journal, 28(3), 243-270.

Porter, M. E. (1980). Competitive strategy. New York: Free Press.

Porter, M. E. (1985). Competitive advantage. New York: Free Press.

Porter, M. E. (1991). Towards a dynamic theory of strategy. Strategic Management Journal, 12(2), 95-117.

Porter, M. E. (1996). What is strategy? Harvard Business Review, 74(6), 61-78.

Sanchez, R. (1995). Strategic flexibility in product competition. Strategic Management Journal, 16, 135-159.

Shane, S., \& Venkataraman, S. (2000). The promise of entrepreneurship as a field of research. Academy of Management Review, 25(1), 217-226.

Teece, D. J., Pisano, G., \& Shuen, A. (1997). Dynamic capabilities and strategic management. Strategic Management Journal, 18(7), 509-533.

Worren, N., Moore, K., \& Cardona, P. (2002). Modularity, strategic flexibility, and firm performance: a study of the home appliance industry. Strategic Management Journal, 23(12), 1123-1140.

Zajac, E. J., Kraatz, M. S., \& Bresser, R. K. F. (2000). Modelling the dynamics of strategic fit: A normative approach to strategic change. Strategic Management Journal, 21(4), 429-453. 